\title{
Designing a Scaffolding for Supporting Personalized Synchronous e-Learning
}

\author{
S.Sengupta ${ }^{1}$, B. Mukherjee ${ }^{2}$, S. Bhattacharya ${ }^{3}$ \\ 1, 2, 3 Dept of CSE/IT, \\ Bengal Institute of Technology, Kolkata-150, India \\ ${ }^{1}$ mesouvik@hotmail. com, ${ }^{2}$ mebulbulmukher jee@gmail.com, ${ }^{3}$ bhattacharya . \\ sudipta@gmail.com
}

\begin{abstract}
The advent of asynchronous web based learning systems has helped the learner in a self paced, personalized and flexible learning style. It can be even more useful with a supportive synchronous tutorial (question-answer) session. The challenge is to provide sufficient information to the instructor about the learner's experience in that particular course. In this paper we have designed an automated scaffolding technique to hold these vital information's about the learner which can be accessed and used by the instructor in the synchronous tutorial session to make the system more adaptive.
\end{abstract}

\section{KEYWORDS}

Asynchronous e-Learning, scaffolding, learner portfolio, adaptive learning;

\section{Introduction}

Contemporary online learning environments are characterized by a growing use of learning management systems, which enable online access to subject matter content, asynchronous online discussions, collaborative learning activities, and online assessment. E-learning expands the scope of independent study and provides a variety of synchronous and asynchronous learning activities.They offer tools for students to engage in asynchronous learning via web based learning contents, generally compatible with "SCORM" standard and then followed by asynchronous interaction with the instructor for solving the problems [7]. Instructor interacts with students over networks and virtually face-to-face at ad hoc times and places. In a traditional class room scenario teacher student interaction plays a vital role in the teaching learning process. The teachers aregenerally aware of the basic competency level and intellect capability of the student on the basis of day to day class performance. The benefit is that then the teacher can adjust the level of his answer or explanation in a manner which is best suited for that particular student or group of students with same level of competency and intellect. In e-learning there is no direct scope to know the basic characteristic of a student. The concept of adaptive e-Learning [1] enables a learner to be presented with content that matches her level of understanding but to solve the personalized problems the facilitator or the instructor should be supported with additional information about the learners. The synchronous student-facilitator collaboration was perceived to be the effective pedagogy [8] that could result in the enhancement of the learning quality. Our aim in this paper is to provide 'scaffolding'that contains all the useful learner information, to the

Natarajan Meghanathan, et al. (Eds): SIPM, FCST, ITCA, WSE, ACSIT, CS \& IT 06, pp. 505-511, 2012. (C) CS \& IT-CSCP 2012 
facilitator. A threefold adaptive policy isproposed which first tracks thelearners'behaviourfrom their web learning environment. Then we have proposed construction of the scaffolding at runtime for a cluster of students with similar attribute values. Finally we have proposed an architecture that adopts and use this scaffolding for aiding the students in a personalized problem solving in e-Learning.

\section{RELATED WORK}

Existing instructional websites record learner's portfolios but they only collect the browsing time and homepage information, without directly provide instructors with more data for further analyzing learner behaviours. In an earlier work by Lee.Cet al. the investigation process of the learners' portfolio left in the e-learning environment is shown and it adopts "data mining" techniques to establish for each cluster of learners the most adaptive learning path pattern, which can provide a "scaffolding" to guide each cluster of learners[3].In another work an advanced Petri Net model to analyze the workflow of a web-based multiple participant's virtual environment has been proposed. Scaffolding is created where behaviours of students are supervised by an intelligent control system, which is programmed by the instructor under a generic interface. The interface is built based on virtual reality and real-time communication technologies[4]. Use of the scaffolding techniques these days are also adopted in mobile-learning environments. The portability and immediate communication properties of mobile devicesindicate the pedagogical potential of mobile devices. In a work learners' behaviours on a website are recorded as learning portfolios and analyzed for behavioural diagnosis or instructional planning. A student model is then built according to the analytical results of learning portfolios and a concept map of the learning domain [5].

\section{TRACKING USER BEHAVIOUR IN ASYNCHRONOUS e-LEARNING}

A rich and detailed user profile plays a key role during the learning activities. Adaptive e-learning takes into account the profile, past behavior, preferences and needs of involved users, as well as the characteristics of the learning environment that they exploit for these activities. In fact, it should handle fairly rich and detailed profiles of users to play a key role in the success of the web based learning programs. The learning portfolios of a learner are collected and stored in learning database for further analysis to draw a nature of a learner. The following strategies are used for this portfolio collection process:

\section{A. User log:}

Most contemporary e-Learning systems have the capability to collect, organize and report data on learners' activities. These may include data on time spent on a learning activity, when it was started and completed, and number of attempts at an assessment item. It may be total time spent on a particular course or average time spent on a particular page etc. In the e-learning system, a learner simultaneously performs multiple learning activities. For example, learners may browse the learning materials, while simultaneously searching for more information on a particular term. So to correctly calculate the reading time, the system subtracts the time that a learner spends in interaction, searching and downloading from the total time spent in the system. While a learner is browsing a learning material, he may leave his browser on the same section and attend other learning-related activities on different topics. Such behavior tends to be associated with a very long reading time. Similarly, learners may browse a section find that they are not interested and skip to other sections. In this case the reading time is very short. To prevent the reading times from being recorded in the above cases, we propose to setlower and upper bounds on the reading 
time. Restated, if a reading time is less than the lower bound or exceeds the upper bound, it is not recorded in the system.

\section{B. Learner's preference:}

The learner's searching history within the portal and also on the web is recorded. The searching style like searching of a particular key word repeated time implies that the place of interest is of highest order. The navigation techniques that whether the learner skips some modules and wants the portfolio to remember that indicates the competence level on that topic is high. Similarly 'favourite's' list maintained by the learner can play a vital role to understand the learner's desire to use and apply the learning.

\section{Learner's interaction record:}

There are three important actors in a formal e-learning context students, instructors, and content. A runtime learning environment sees the interaction among the three actors and these information are very important to the construction of the scaffolding.

\section{a) Learner to Content interaction:}

Today's learning content in e-learning world is very much interactive with the user with association of different multimedia data, animations, instructions, simulations, micro worlds, and presentation creation tools. So, the nature of the request of content by learner, submission of presentation and frequencies of file download and upload by a student help to draw the graph of performance and confidence level of a learner.

\section{b) Learner to Learner interaction:}

The student-peer collaboration enabled the students to link up different ideas and to share knowledge and it induced motivation that contributed to positive learning outcomes. Collaborative and cooperative learning asynchronously through mail, messaging, blogging or synchronously by chatting or video conferencing are available in modern adaptive e-learning systems. The nature of asking questions, sharing answers and frequencies of doing these can help to analyze a particular learner's characteristic and interest of study.

Table 1. A diagram of six interactive modes possible

\begin{tabular}{|l|l|l|l|}
\hline & Learner & Facilitator & Content \\
\hline Learner & $\begin{array}{l}\text { Cooperative } \\
\text { And } \\
\text { collaborative } \\
\text { learning }\end{array}$ & $\begin{array}{l}\text { Asking } \\
\text { question, } \\
\text { Doubt } \\
\text { clearance }\end{array}$ & $\begin{array}{l}\text { Self pace } \\
\text { learning }\end{array}$ \\
\hline Facilitator & $\begin{array}{l}\text { Interacting } \\
\text { And } \\
\text { facilitating }\end{array}$ & $\begin{array}{l}\text { Sharing } \\
\text { Knowledge \& } \\
\text { experience }\end{array}$ & Making \\
\hline Content & $\begin{array}{l}\text { Interacting } \\
\text { interfacing }\end{array}$ & $\begin{array}{l}\text { Interacting } \\
\text { interfacing }\end{array}$ & $\begin{array}{l}\text { Interacting } \\
\text { interfacing }\end{array}$ \\
\hline
\end{tabular}




\section{c) Learner to Instructor interaction:}

In e-learning environment one student can interact with the instructor via mail or blog. The nature of question (e.g if it is subjective or objective), the frequencies of asking question and the relevancy of it with the subject may judge a learner's intellect. This type of interactions can be arranged in a synchronous way by chatting, audio or video conferencing. In order to make this more personalized sufficient information about the students' learning behavior should be provided to the Instructor.

\section{Learning Path:}

The adaptive release of content within e-learning courses enables the learner to experience an individualized learning path. It also allows the facilitator to create rules for delivering content to the learner upon specific tasks which leads to the achievement of the course learning objectives. It can be implemented with prompts and cues that encourage learners to think about their learning process and to utilize appropriate learning strategies, in essence developing the learners' meta cognitive skills. To improve learning performance, a "scaffolding learning paths," is designed [3] which provide different learning patterns based on the learning abilities of different learners, and give learners an adaptive navigational learning map which describes the connected paths of time sequence of a learner's visit of the lessons of the teaching materials. Scaffolding learning theory proposes that instructors should construct different learning scaffolding stands according to level of ability development and learning progress of different learners [2]

\section{E. Learner's assessment:}

In web-based e-learning system integrated assistance and assessment tools are required that offers instruction to students while providing a detailed evaluation of their abilities by theinstructors [6]. Many studies have demonstrated that the records of student learning paths and learning performance in the e-Learning system can be provided as a reference for instructors to evaluate the learning accomplishments of students and diagnose their learning difficulties, hence, through "learning portfolio monitoring" in the "intelligent e-learning system," the investigation records the learning path data of learners[3]. The assessment of student's performance enables the construction of a rich student profile that records student progress and characteristics.

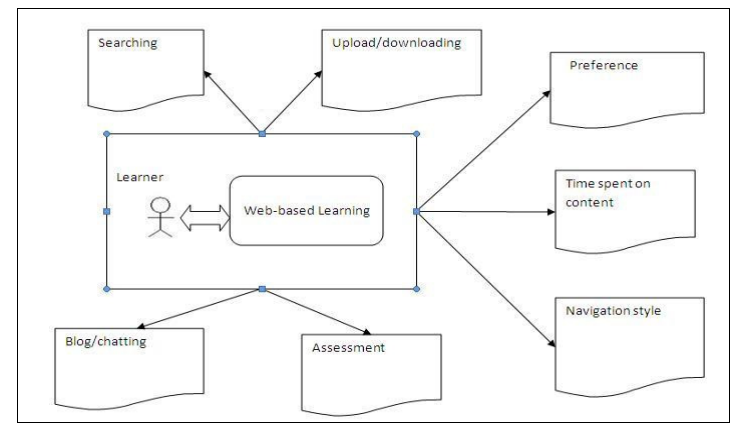

Figure 1. Learner's information tracking

\section{DESIGNING THE SCAFFOLDING}

Our proposed framework built the scaffolding by investigating the learner's information as described in section 3. As shown in figure 2 different activities are tracked from the asynchronous 
web based learning environment. The students with similar track record and behaviour are clustered together by application of data mining tools on the obtained data.

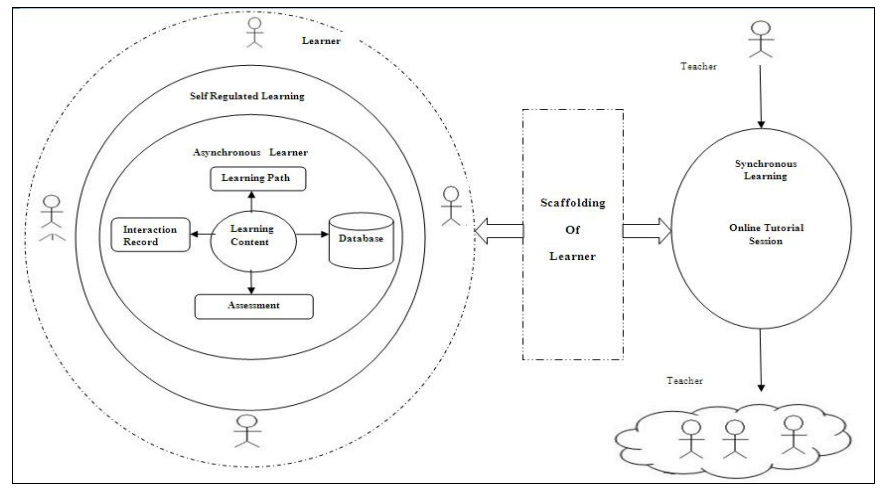

Figure2.Proposed Scaffolding Architecture

The scaffolding is created only at runtime after the Learner-Instructor interactive session is initiated. It holds the necessary information about the learner or group of learners about their subject competence, base- knowledge, weakness, preference etc. The instructor may reframe her answer or illustration that suits the learner most.

\section{USE OF SCAFFOLDING IN SYNCHRONOUS SYSTEM}

Next we propose to use of this scaffolding for the synchronous interaction session between learners and instructors. This can have its best result when it is used as tutorial session which is supplemented to the self regulated learning by the learner. We propose to use different data mining tools to classify the learners. For numerical data available from average time spent on $a$ web page, number of uploads and downloads, assessment score etc. the Euclidian distance based clustering algorithms like k-medoid, DBSCAN etc. can be used, where as for non numeric data like searching, navigation path, blog data categorical clustering algorithms likeSTIRR,ROCK, CACTUS are better suited. The objective of the clustering is to find out students with similar comprehensive level and expertise which is very helpful for the instructors in conducting live tutorial sessions for doubt clearance and question answering.

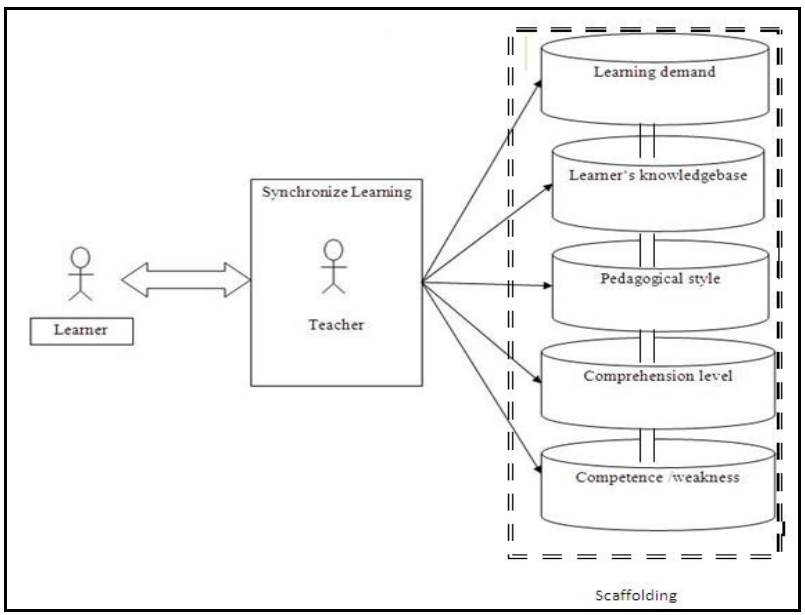

Figure 3. Adaptation of Scaffolding 


\section{CONCLUSION}

In this paper we tried to propose a framework of scaffolding which helps the learner as well as the instructor in the live tutorial or question answer session in the synchronous medium like chatting, video calling, conferencing etc. The scaffold provides useful information about the learner's behavior based on his self regulated learning to the instructor thus make the system more adaptive and personalized. This framework is at the higher level of abstraction, the technical details of implementing different phases of this scaffolding depends on the choice of the designer of the implementing system, we have given only the outline of how this can be done.

\section{REFERENCES}

[1] Razzaq.L, Heffernan.T.N, "Towards Designing a User-Adaptive Web-Based E-Learning System" CHI, ACM 978-1-60558-012-8/08/04,Florence, Italy ,April , 2008.

[2] Yang, C.C. "A Study of the Application of Scaffolding Theory to the Acid and Alkaline Chemicals Website of Primary School." Master thesis, Graduate School of Applied Chemistry, Providence University, 2000.

[3] Lee.C.H,Lee.G.G,YunghoLeu.Y, "Analysis on the Adaptive Scaffolding Learning Path and the Learning Performance of e-Learning ", WSEAS TRANSACTIONS on INFORMATION SCIENCE \& APPLICATIONS, ISSN: 1790-0832, Issue 4, Volume 5,pp,320-330, April 2008.

[4] 4. Yen.S.H,Lawrence .Y, Deng.L.Y, Chen.Y.H,"Scaffolding for Activity Supervision and SelfRegulation in Virtual University,Tamkang" Journal of Science and Engineering, Vol. 8, No 2, pp. $133 \_146,2005$.

[5] Chen.G.D,Chang.C.K,Wang.C.Y,"Ubiquitous learning website: Scaffold learners by mobile devices with information-aware techniques", Computers \& Education 50,pp, 77-90,2008.

[6] Razzaq, Heffernan, Koedinger, Feng, Nuzzo-Jones, Junker, Macasek, Rasmussen, Turner \&Walonoski "Blending Assessment and Instructional Assistance. In Nadia Nedjah, LuizadeMacedoMourelle, Mario Neto Borges and NivalNunesde Almeida (Eds). Intelligent Educational Machines within the Intelligent Systems Engineering Book Series.SpringerBerlin / Heidelberg. pp, 23-49,2007.

[7] Shareable Content Object Reference Model (SCORM) U.S Government CAdvanced Distributed Learning. URL: http://www.adlnet.gov/scorm

[8] FauziahSulaiman,HanafiAtan, Rozhan M Idrus\&HishamDzakiria, "Problem-Based Learning: A Study of the Web-Based Synchronous Collaboration", Malaysian Online Journal of Instructional Technology (MOJIT) Vol. 1, No. 2, pp 58-66 December 2004. 
Authors

Souvik Sengupta is an Assistant Professor in the Computer Science Department of Bengal Institute of Technology, India . He has obtained his Master of Technology form West Bengal University of Technology, India in 2008. He is currently performing his research work under the $\mathrm{PhD}$ program of the Department of Information Technology of the university of Calcutta ,India. He has 10 international journal and conference papers published in last 3 years. He has also served as a visiting faculty in the M.Tech program of Department of Computer Science of National Institute of Technical Teachers' Training and Research, Kolkata, India. His areas of research interests include Web-based Learning, Formal software engineering, Multimedia Database, Data mining, Software engineering, Artificial Intelligence etc.

Bulbul Mukherjee is in Computer Science Department of Bengal Institute of Technology, India; her research interest is in Software Engineering, Distributed Database, Artificial Intelligence, E-learning. She is pursuing Master of Technology in Multimedia \& System Software from West Bengal University of Technology, India. She has one paper in 'Petri-Net modeling' published in a National Conference ETEI-2012.

Sudipta Bhattacharya is working as Assistant Professor in the Department of Computer Science and Information Technology at Bengal Institute of Technology, Kolkata, India. He received his Bachelor of .Technology,(IT) from West Bengal University of Technology, India , Master of Technology(IT) from Bengal Engineering and Science University, Shibpur, India. $\mathrm{He}$ has 5 International Conference Papers and one International Journal Paper published in last 3 years. His area of research interest Data mining, System \&Internet Security and Networking, E-learning, Artificial Intelligence
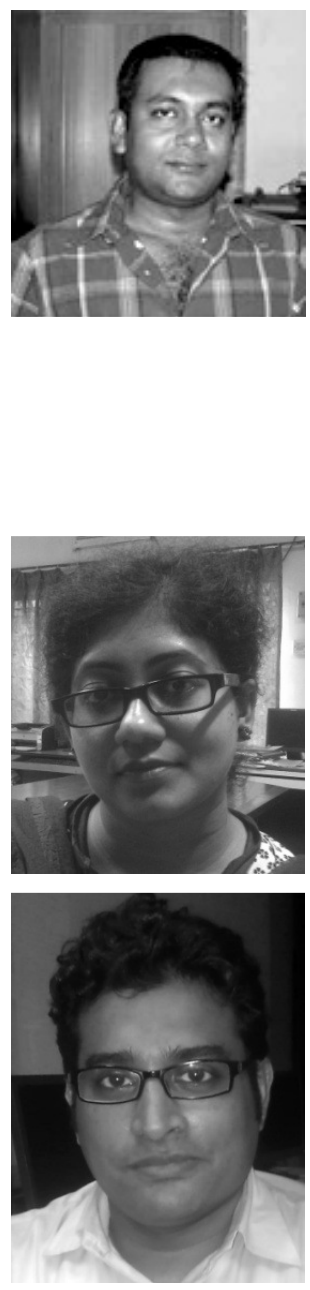